\title{
Prevalence of ocular manifestations of leprosy in Port Moresby, Papua New Guinea
}

\author{
ROGER DETHLEFS \\ From the Ophthalmic Department, Port Moresby General Hospital, Papua New Guinea
}

SUMMARY The prevalence of ocular lesions in patients with leprosy attending the Port Moresby General Hospital leprosy clinic was $52 \%$. The prevalence of potentially sight threatening lesions in these patients was $12 \%$. Their mean age was 26.3 years, and the mean estimated duration of disease was $7 \cdot 2$ years.

In Papua New Guinea today there are more than 8000 known cases of Hansen's disease and it is estimated that approximately $0.5-0.7 \%$ of the population of Papua New Guinea or between 13000 and 20000 people suffer from it.

With the aid of modern medicines and a functioning leprosy control programme, however, the ocular morbidity of the disease is much less evident than that reported in some other countries. ${ }^{12}$ Those managing leprosy patients in Port Moresby General Hospital have the impression that serious ocular complications are rare in leprosy patients in Port Moresby. An attempt is made here to document the prevalence and type of ocular complications seen in leprosy patients in Port Moresby.

\section{Materials and methods}

One hundred and ten patients were sent in an arbitrary fashion from the Port Moresby General Hospital leprosy outpatient department to the eye clinic for ocular examination during a period from July to November 1978. In each case the name and age of the patient, the duration of the disease, the leprosy classification, and past treatment were noted. The ocular examination included testing of visual acuity, and macroscopic examination of the eyebrows, eyelids, and epibulbar region. The function of the facial nerve was tested and fundoscopy performed. Slit-lamp biomicroscopy was then carried out to elicit any lesions of cornea, anterior chamber, iris, and lens. Lastly the sensation of the corneae was tested with a wisp of cotton wool under microscopic control.

Correspondence to Dr R. Dethlefs, Senior Specialist Medical Officer (Ophthalmology), Post Office Box 1403, Boroko, Papua New Guinea.
Table 1 The prevalence of ocular lesions according to leprosy type

\begin{tabular}{lccc}
\hline & Tuberculoid & Borderline & Lepromatous \\
\hline Madarosis & - & 22 & 27 \\
Lid infiltration & - & 6 & 8 \\
Epibulbar lesions & - & - & - \\
Superficial keratitis & - & 10 & 10 \\
Corneal hypoaesthesia & - & 7 & 7 \\
Band keratopathy & - & - & - \\
Flare & - & 1 & 3 \\
Cells & - & 1 & 4 \\
Posterior synechiae & - & - & 1 \\
Keratic precipitates & - & 2 & 4 \\
Iris pearls & - & - & 3 \\
Choroidal lesions & - & - & - \\
Interstitial keratitis & - & - & 1 \\
Leprous pannus & - & - & - \\
Lagophthalmos & - & 6 & - \\
Total & 9 & 70 & 30 \\
\hline
\end{tabular}

To check that the group of patients examined was not a biased population the leprosy register of all patients attending the leprosy outpatients' department of Port Moresby General Hospital was examined and the mean age and duration of disease since registration was recorded.

\section{Results}

The above mentioned parameters were recorded in the 110 patients examined and are tabulated in Table 1. One case (classified as 'indeterminate') 
was discarded from the series because it could not be included in the 3 major classification types of leprosy. Those with potentially sight threatening lesions are tabulated in Tables 2 and 3.

The prevalence of ocular complications of leprosy in the patients examined was $52 \%$, while the prevalence of potentially sight threatening lesions was $12 \%$. These lesions were lagophthalmos and anterior uveitis. The majority of cases of uveitis (5 out of 7) occurred in patients with lepromatous leprosy. No potentially sight threatening lesions occurred in tuberculoid leprosy patients.

Of the 110 patients examined, the mean estimated duration of the disease was $7 \cdot 2$ years, while the mean age of the patients was $26 \cdot 3$ years. 777 leprosy outpatients were recorded on the leprosy register of the outpatients department at Port Moresby General Hospital as currently attending the hospital. Their mean age was 28.3 years, and the mean duration of disease since registration was 6.5 years.

\section{Discussion}

The prevalence of ocular lesions varies from series to series depending on race, average duration of

Table 2 Cases of lagophthalmos

\begin{tabular}{llll}
\hline Case & $\begin{array}{l}\text { Age } \\
\text { (years) }\end{array}$ & $\begin{array}{l}\text { Estimated duration } \\
\text { of disease } \\
\text { (years) }\end{array}$ & $\begin{array}{l}\text { Leprosy } \\
\text { classification* }\end{array}$ \\
\hline 2 & 36 & 10 & BB \\
10 & 35 & 10 & BT \\
40 & 18 & 3 & BL \\
44 & 30 & 15 & Neuritic (BT) \\
58 & 11 & 4 & Neuritic (BT) \\
66 & 37 & 9 & BT \\
\hline
\end{tabular}

-BB = borderline leprosy. $\mathbf{B T}=$ borderline tuberculoid leprosy. $\mathrm{BL}=$ borderline lepromatous leprosy.

Table 3 Cases of old or active anterior uveitis

\begin{tabular}{llll}
\hline Case & $\begin{array}{l}\text { Age } \\
\text { (years) }\end{array}$ & $\begin{array}{l}\text { Estimated duration } \\
\text { of disease } \\
\text { (years) }\end{array}$ & $\begin{array}{l}\text { Leprosy } \\
\text { classification* }\end{array}$ \\
\hline 6 & 33 & 1 & BB \\
11 & 32 & 18 & LL \\
12 & 45 & 8 & BB \\
39 & 18 & 15 & LL \\
67 & 40 & 8 & LL \\
79 & 36 & 19 & LL \\
97 & 36 & 27 & LL \\
\hline
\end{tabular}

*BB = borderline leprosy. $L L=$ polar lepromatous leprosy. disease in the series, ${ }^{1-6}$ and the criteria and equipment used for the diagnosis. Shields ${ }^{2}$ quotes prevalence rates by several different authors varying between $6 \%$ and $90 \%$. In his own series he found a prevalence of $72 \%$. However, he stresses the prevalence of potentially sight threatening lesions, which was $33 \%$. These lesions were keratitis, iritis, lagophthalmos, and secondary glaucoma.

In contrast to Shields's series the Port Moresby series has a much lower prevalence of ocular complications and potentially sight threatening lesions. The causes of sight threatening lesions also differ in that neither keratitis, which threatened sight, nor secondary glaucoma, were found in the Port Moresby series. The reasons for this difference might include bias in populations studied, the efficiency of the control programme, racial variation, the average duration of the disease, and the average age of the group studied. The most obvious reasons for the different prevalences is that the mean age of Shields's patients was 55 years and the mean duration of disease 24 years-a much older group of patients than in the Port Moresby series.

Since the mean age and mean estimated duration of disease of the 110 patients examined corresponds closely with that of 777 patients currently attending the leprosy outpatients department at Port Moresby. The sample reflects fairly accurately the overall prevalence of ocular complications of leprosy in leprosy sufferers in Port Moresby.

Uveitis, as in other series, ${ }^{2357}$ occurred most commonly in lepromatous leprosy patients. As stressed by Hobbs, ${ }^{5}$ all cases except one had normal visual acuity and white (noninflamed) eyes indicating the chronic low-grade nature of the process and requiring slit-lamp biomicroscopy for diagnosis.

The prevalence of lagophthalmos was similar to that of other series. ${ }^{235}$ In this series all cases were of borderline leprosy type. This is consistent with motor nerve lesions in leprosy, mostly occurring in borderline cases or very late in the course of lepromatous leprosy.

The visual deficit varies from series to series. Shields's ${ }^{2}$ series showed $10 \%$ visually handicapped, while Harrell ${ }^{1}$ quotes $50 \%$ with $6 / 60$ vision or less in 1 or both eyes. In this series there were only 4 patients with visual acuity less than $6 / 9$ in 1 eye. Three of the cases had suffered trauma to the affected eye leaving them with visual acuity of $6 / 60$ or less. One patient had sufficient superficial punctate keratitis to reduce the visual acuity to $6 / 12$ in 1 eye. This singular lack of permanent visual deficit again reflects the factors mentioned in relation to the prevalence of sight threatening lesions.

Keratitis is mentioned as a potentially sight 
threatening lesion in some series ${ }^{25}$-in this series however, there was only 1 case of interstitial keratitis affecting peripheral cornea only and 1 case of nonvascularised superficial keratitis with 'chalk flake'8 opacities in the upper cornea adjacent to the limbus. The remaining 18 cases were superficial punctate lesions which stained with fluorescein and were due to either lagophthalmos and exposure or were neurotrophic due to trigeminal nerve deficit. The fact that 6 cases had superficial punctate keratitis without lagophthalmos or hypoaesthesia of the cornea can probably be explained by the fact that the test used for hypoaesthesia is a gross one and can give rise to false negative results.

The author gratefully acknowledges the contributions made towards this paper by Dr A. Griew in statistical advice, and Dr H. Ree and the staff of the leprosy outpatients depart- ment of Port Moresby General Hospital in supplying clinical advice and patients.

\section{References}

1 Harrel JD. Ocular leprosy in the Canal Zone. Int J Lepr 1977;45:1-8.

2 Shields JA, Waring GO, Monte LG. Ocular findings in leprosy. Am J Ophthalmol 1974;77:880-890.

3 Emiru VP. Ocular leprosy in Uganda. $B r J$ Ophthalmol 1970;54:740-743.

4 McLaren DS, Shaw MJ, Dalley KR. Eye disease in leprosy patients; a study in central Tanganyika. Int J Lepr 1961; 29:20-28.

5 Ticho U, Ben Sira I. Ocular leprosy in Malawi. Br J Ophthalmol 1970;54:107-112.

6 Weerekoon L. Ocular leprosy in Ceylon. Br J Ophthalmol $1969 ; 53: 457-465$.

7 Hobbs HE. Leprotic iritis and blindness. Int J Lepr 1972; 40:366-374.

8 Choyce DP. Diagnosis and management of ocular leprosy. Br J Ophthalmol 1969;53:217-223. 